\title{
How can we reduce the economic burden of diabetes?
}

In the US, the economic burden of diabetes mellitus was a massive \$27 billion in 2007 and could increase to $\$ 190$ billion by 2020 . Stuart et al. outline a possible approach to reduce diabetes-related health-care spending.

The researchers used US Medicare Current Beneficiary Survey data from 1997 to 2004 to examine the relationship between annual prescription fills and hospitalization risk, annual hospitalized days and Medicare spending. The analysis included 7,441 Medicare beneficiaries.

Seven groups of diabetes drugs were studied: traditional oral antidiabetic agents, contemporary oral diabetic agents, insulins, angiotensin-converting-enzyme inhibitors, angiotensin II receptor blockers, statins, and other lipid-lowering agents.

The investigators found that almost onethird of the patients had been hospitalized each year; this figure was $>40 \%$ for patients who used insulin. Mean annual Medicare spending was highest for patients who used insulin $(\$ 16,950)$ and lowest for those who used traditional oral antidiabetic agents $(\$ 8,565)$.

Consistently high use of four of the drug groups-traditional oral antidiabetic agents, angiotensin-converting-enzyme inhibitors, angiotensin II receptor blockers and statinsreduced risk of hospitalizations, number of hospital days and Medicare costs.

These findings highlight an economic case for promotion of increased use of approved medications.

\section{Carol Wilson}

Original article Stuart, B. C. et al. Increased persistency in medication use by US Medicare beneficiaries with diabetes is associated with lower hospitalization rates and cost savings. Diabetes Care [doi:10.2337/dc08-1311] (2009). 